\title{
Relationship Between Spontaneous Expiratory Flow-Volume Curve Pattern and Air-Flow Obstruction in Elderly COPD Patients
}

\author{
Masafumi Nozoe PT PhD, Kyoshi Mase PT PhD, Shigefumi Murakami PT, \\ Makoto Okada PT, Tomoyuki Ogino PT MSc, Kazuhiro Matsushita PT, \\ Sachie Takashima PT MSc, Noriyasu Yamamoto MD PhD, Yoshihiro Fukuda MD PhD, \\ and Kazuhisa Domen MD PhD
}

\begin{abstract}
BACKGROUND: Assessment of the degree of air-flow obstruction is important for determining the treatment strategy in COPD patients. However, in some elderly COPD patients, measuring FVC is impossible because of cognitive dysfunction or severe dyspnea. In such patients a simple test of airways obstruction requiring only a short run of tidal breathing would be useful. We studied whether the spontaneous expiratory flow-volume (SEFV) curve pattern reflects the degree of airflow obstruction in elderly COPD patients. METHODS: In 34 elderly subjects (mean \pm SD age $80 \pm 7 \mathrm{y}$ ) with stable COPD (percent-of-predicted $\mathrm{FEV}_{1} 39.0 \pm 18.5 \%$ ), and 12 age-matched healthy subjects, we measured FVC and recorded flow-volume curves during quiet breathing. We studied the SEFV curve patterns (concavity/convexity), spirometry results, breathing patterns, and demographics. The SEFV curve concavity/convexity prediction accuracy was examined by calculating the receiver operating characteristic curves, cutoff values, area under the curve, sensitivity, and specificity. RESULTS: Fourteen subjects with COPD had a concave SEFV curve. All the healthy subjects had convex SEFV curves. The COPD subjects who had concave SEFV curves often had very severe airway obstruction. The percent-of-predicted $\mathrm{FEV}_{1} \%(32.4 \%)$ was the most powerful SEFV curve concavity predictor (area under the curve $0.92,95 \%$ CI $0.83-1.00$ ), and had the highest sensitivity $(0.93)$ and specificity $(0.88)$. CONCLUSIONS: Concavity of the SEFV curve obtained during tidal breathing may be a useful test for determining the presence of very severe obstruction in elderly patients unable to perform a satisfactory FVC maneuver. Key words: COPD; flow-volume curve; air-flow obstruction; respiratory function test. [Respir Care 2013;58(10):1643-1648. (C) 2013 Daedalus Enterprises]
\end{abstract}

\section{Introduction}

Measurement of FVC is a clinically useful test that is required to diagnose air-flow obstruction and determine the severity of obstruction. ${ }^{1}$ However, FVC often cannot

\footnotetext{
Dr Nozoe, Mr Murakami, Mr Okada, Mr Ogino, and Mr Matsushita are affiliated with the Department of Rehabilitation; Dr Yamamoto is affiliated with the Department of Functional Regenerative Science; Dr Fukuda is affiliated with the Department of General Medicine and Community Health Science, Hyogo College of Medicine, Sasayama, Hyogo, Japan. Dr Mase and Ms Takashima are affiliated with the Department of Physical Therapy, Faculty of Nursing and Rehabilitation, Konan Women's University, Kobe, Hyogo, Japan. Dr Domen is affiliated with the Department of Physical Medicine and Rehabilitation Science, Hyogo College of Medicine, Nishinomiya, Hyogo, Japan.
}

be measured in elderly patients with problems such as cognitive dysfunction or severe dyspnea, because FVC depends on the patient's respiratory effort. Recently, as a technique to identify pathology, the oscillation method has been used for the measurement of resting breathing, even in these patients. ${ }^{2}$ However, the oscillation method is dif-

\footnotetext{
The authors have disclosed no conflicts of interest.

Correspondence: Masafumi Nozoe PT PhD, Department of Rehabilitation, Sasayama Medical Center, Hyogo College of Medicine, Kurooka 5, Sasayama, Hyogo Prefecture 669-2321, Japan. E-mail: sasareha@hyomed.ac.jp.
}

DOI: $10.4187 /$ respcare.02296 
ficult to use in the clinical setting because the required equipment is large and expensive. On the other hand, assessment of the spontaneous expiratory flow-volume (SEFV) curve has been reported as a method to evaluate the severity of airway obstruction, which has the advantage that it is easily measured via spirometry during quiet breathing. ${ }^{3-10}$ Shortening of the time to reach the peak expiratory flow ${ }^{3}$ and the slope of the late SEFV curve, ${ }^{4}$ which can be obtained from the SEFV curve, has been reported to be related to airway obstruction. Moreover, a method to assess the pattern of the SEFV curve has been reported, and concavity of the SEFV curve has been found to be related to expiratory flow limitation. ${ }^{9,10}$ The SEFV curve could be used clinically if there is an association between SEFV curve shape and the severity of airway obstruction, because the SEFV curve shape can be easily evaluated. We studied whether the SEFV curve shape reflects the degree of airway obstruction in elderly COPD patients.

\section{Methods}

This study was approved by the ethics committee of Hyogo College of Medicine, Hyogo, Japan, and all subjects gave written, informed consent in advance.

\section{Subjects}

A total of 34 , clinically stable, elderly COPD patients (Table 1) who were receiving pulmonary rehabilitation at the Sasayama Medical Center, Hyogo College of Medicine, and who could perform spirometry according to the

Table 1. Subject Characteristics and Resting Pulmonary Function $(n=34)$

\begin{tabular}{lcc}
\hline \hline & Value & Range \\
\hline Male/female, no. & $27 / 7$ & \\
Age, y & $80 \pm 7$ & $65-92$ \\
Weight, kg & $47 \pm 9$ & $30-71$ \\
Height, cm & $158 \pm 7$ & $143-172$ \\
Body mass index, kg/m ${ }^{2}$ & $19 \pm 3$ & $14-28$ \\
FEV ${ }_{1}, \mathrm{~L}$ & $0.85 \pm 0.46$ & $0.26-2.10$ \\
FEV $\%$ predicted & $39.0 \pm 18.5$ & $18.2-79.7$ \\
FEV/FVC, \% & $44.2 \pm 14.1$ & $22.0-68.7$ \\
FVC, L & $1.78 \pm 0.71$ & $0.70-3.53$ \\
FVC \% predicted & $62.7 \pm 19.9$ & $27.2-106.3$ \\
Required home oxygen, no. & 21 & \\
GOLD stage, no. & & \\
2 & 9 & \\
3 & 11 & \\
4 & 14 & \\
\hline Global Initiative for Chronic Obstructive Lung Disease & \\
\hline
\end{tabular}

\section{QUICK LOOK}

\section{Current knowledge}

Assessment of air-flow obstruction is important for determining the treatment strategy in patients with COPD. However, in some patients the FVC maneuver is impossible because of cognitive dysfunction or severe dyspnea, and it would be useful to have a simple test for obstruction that does not require patient cooperation.

\section{What this paper contributes to our knowledge}

Concavity of the spontaneous expiratory flow-volume curve during tidal breathing may help identify very severe obstruction in patients who can not perform the FVC maneuver. Further studies are required to determine the appropriate population for use of this technique.

American Thoracic Society/European Respiratory Society task force guidelines, participated. ${ }^{1}$ The COPD subjects were clinically stable for $\geq 4$ weeks. The exclusion criteria were: suspected asthma; other conditions that could contribute to dyspnea or exercise limitation, such as heart failure or metabolic disorders; and neuromuscular comorbidity that could limit the measurements. Twelve agematched healthy subjects were also studied.

\section{Procedures}

All the measurements were done with the subject seated. A hot-wire spirometer (AE300-s, Minato Medical Science, Osaka, Japan) connected to a mouthpiece was used to measure FVC and to record flow and volume during $1 \mathrm{~min}$ of quiet breathing. All the subjects performed the inspiratory capacity maneuver at the start and at the end of quiet breathing, to correct for possible "drift" caused by mechanical error. ${ }^{11}$ Mastery of the inspiratory capacity maneuver was ensured by having the subject practice it beforehand; however, some subjects often could not start inspiratory capacity measurement from functional residual capacity. We also measured "actual inspiratory capacity" volume at the start and at the end of quiet breathing. ${ }^{12}$ To control measurement quality, all the subjects obtained "actual inspiratory capacity" volume variation of $<10 \%$. The FVC measurements were done according to the American Thoracic Society/European Respiratory Society task force guidelines. ${ }^{1}$

The lung volume and flow data were examined using an analyzing system (PowerLab, ADInstruments, Dunedin, New Zealand). The last 5 breaths were analyzed breath-bybreath, and for each subject we calculated the mean inspiratory time $\left(\mathrm{T}_{\mathrm{I}}\right)$, expiratory time $\left(\mathrm{T}_{\mathrm{E}}\right)$, total breathing cycle time 

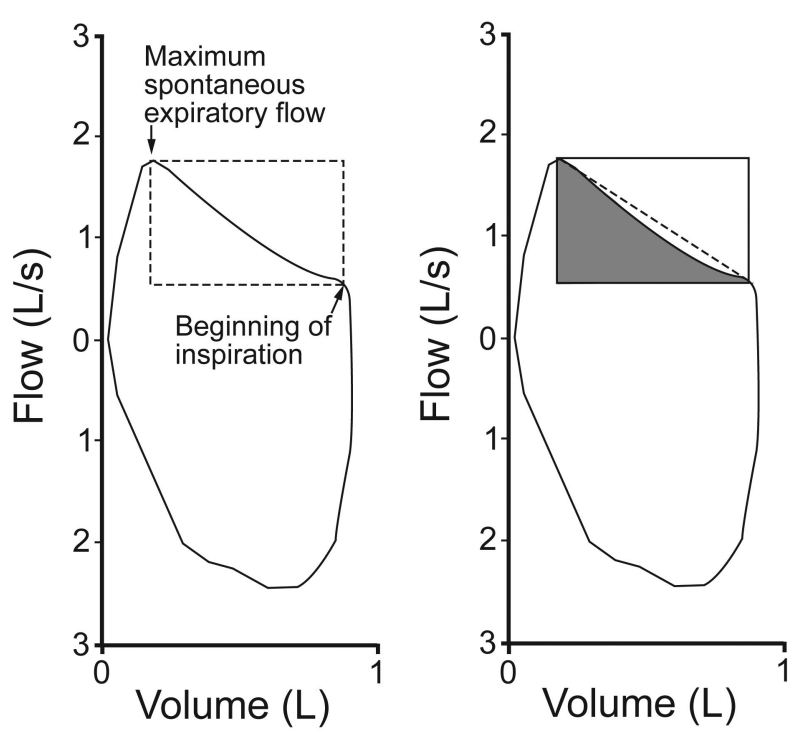

Fig. 1. Method to calculate the rectangular area ratio. Left: The maximum spontaneous expiratory flow and the beginning of inspiration are first identified. Right: The area of the rectangle (with $\dot{\mathrm{V}}_{\text {max }}$ and $\dot{\mathrm{V}}_{\text {ee }}$ as vertices) is calculated. The area delimited by the spontaneous expiratory flow-volume (SEFV) curve in the rectangle is calculated, and then the SEFV curve area to rectangle area ratio is calculated.

$\left(\mathrm{T}_{\text {tot }}\right)$, duty cycle $\left(\mathrm{T}_{\mathrm{I}} / \mathrm{T}_{\text {tot }}\right)$, tidal volume $\left(\mathrm{V}_{\mathrm{T}}\right)$, mean inspiratory flow $\left(\mathrm{V}_{\mathrm{T}} / \mathrm{T}_{\mathrm{I}}\right)$, and mean expiratory flow $\left(\mathrm{V}_{\mathrm{T}} / \mathrm{T}_{\mathrm{E}}\right)$.

We studied the SEFV curves from the last 5 breaths. Assessment of the SEFV curves was according to the methods of Ma et al. ${ }^{10}$ More specifically, 2 critical anchoring points are determined first: the maximum spontaneous expiratory flow; and the point at which the expiratory flow takes a sharp decline, signaling the beginning of inspiration, which was defined as the point associated with the greatest difference between the slopes of the SEFV curve during the last $0.25 \mathrm{~s}$. We calculated the area of the rectangle with the 2 points as vertices, the area delimited by the SEFV curve in the rectangle, and the ratio of the delimited area to the rectangle area (rectangular area ratio) (Fig. 1). The rectangular area ratio was calculated for each breath, and a mean value for each subject was obtained (Fig. 2). A mean rectangular area ratio $<0.5$ signifies concavity, whereas a value $\geq 0.5$ signifies convexity.

The reproducibility of the rectangular area ratio measurements was evaluated by re-testing in 10 subjects ( 2 with GOLD stage 2, 3 with GOLD stage 3, and 5 with GOLD stage 4), after the first measurements, on the same day. Close correlations were found between the first and second rectangular area ratios. Linear regression analyses of the first and second measurements provided the following equation:

First measurement $=1.112$ second measurement -0.043

for which $\mathrm{r}=0.96$ and $P<.001$.

\section{Statistical Analysis}

The results are shown as mean $\pm \mathrm{SD}$. $\mathrm{FEV}_{1}$ and FVC are expressed as percent-of-predicted values for age, sex, and height, established by the Japanese Respiratory Society. ${ }^{13}$ The Mann-Whitney U test was used to compare the rectangular area ratios between the healthy subjects and the COPD subjects. Group comparisons of demographic characteristics, lung function, breathing pattern, and rectangular area ratio were performed using one-way analysis of variance (ANOVA) and Bonferroni post hoc comparison. The cutoff value to predict SEFV curve pattern (convexity/concavity) was determined for each variable that showed a significant difference in ANOVA (the spirometric values included only predicted values) with the receiver operating characteristic curve. We calculated sensitivity, specificity, positive predictive value, negative predictive value, likelihood ratio of a positive test, likelihood ratio of a negative test, diagnostic accuracy, and area under the receiver operating characteristic curve. All tests were performed at a significance level of $P<.05$. Analyses were performed with statistics software (SPSS 18, SPSS, Chicago, Illinois).

\section{Results}

The mean rectangular area ratio for the COPD subjects was $0.507 \pm 0.090 ; 14$ SEFV curves showed concavity, and the others showed convexity. In the healthy subjects the mean rectangular area ratio was $0.664 \pm 0.069$. None of the SEFV curves from the healthy subjects showed concavity. As a result, the rectangular area ratio was smaller in the COPD subjects than in the healthy subjects $(P<.001)$.

Table 2 shows the demographic characteristics, lung function, breathing patterns, and rectangular area ratios according to SEFV shape. There were significant differences in $\mathrm{FEV}_{1}, \mathrm{FEV}_{1} \%, \mathrm{FEV} / \mathrm{FVC}, \mathrm{FVC}, \mathrm{FVC} \%, \mathrm{~T}_{\mathrm{I}}$, $\mathrm{T}_{\mathrm{I}} / \mathrm{T}_{\text {tot }}$, and $\mathrm{V}_{\mathrm{T}} / \mathrm{T}_{\mathrm{I}}$ via ANOVA. Eleven subjects in the concavity group had very severe air-flow obstruction, and the remaining 3 subjects with concavity had severe obstruction ( $\mathrm{FEV}_{1} \% 30-50 \%$, GOLD stage 3$)$. On the other hand, age, height, body mass, body mass index, and other breathing pattern indices were not significantly different.

Quality indicators of the 6 indices that showed significant differences via ANOVA used to predict the SEFV curve pattern are shown in Table 3. Cutoff values (calculated from the receiver operating characteristic curves) for $\mathrm{FEV}_{1} \%, \mathrm{FVC} \%, \mathrm{~T}_{\mathrm{I}} / \mathrm{T}_{\text {tot }}, \mathrm{FEV} / \mathrm{FVC}, \mathrm{T}_{\mathrm{I}}$, and $\mathrm{V}_{\mathrm{T}} / \mathrm{T}_{\mathrm{I}}$ were $32.4 \%, 60.8 \%, 0.39,46.7 \%, 1.06 \mathrm{~s}$, and $0.52 \mathrm{~L} / \mathrm{s}$, respectively. $\mathrm{FEV}_{1} \%$ showed the best diagnostic accuracy (0.92), followed by $\mathrm{FVC} \%(0.89), \mathrm{T}_{\mathrm{I}} / \mathrm{T}_{\text {tot }}(0.81), \mathrm{FEV} /$ FVC (0.80), $\mathrm{T}_{\mathrm{I}}(0.77)$, and $\mathrm{V}_{\mathrm{T}} / \mathrm{T}_{\mathrm{I}}(0.61)$ (Table 4). The predictive performance of a clinically useful value $\left(\mathrm{FEV}_{1} \%\right.$ 

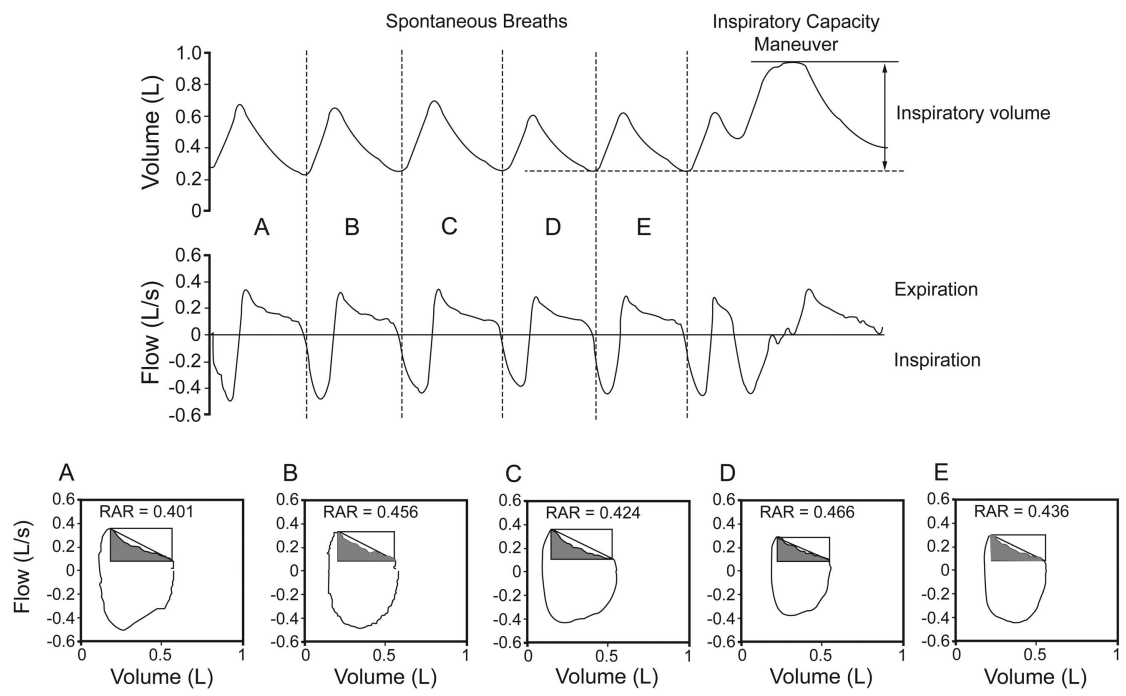

Fig. 2. Changes in lung volume, flow, and rectangular area ratio. The upper panel shows the volume-time and flow-time curves from 5 quiet spontaneous tidal breaths (A through $\mathrm{E}$ ) and then from the inspiratory capacity maneuver. The lower panel shows the corresponding flow-volume curves and rectangular area ratios (RARs).

Table 2. Demographics, Lung Function, Breathing Pattern, and Rectangular Area Ratio

\begin{tabular}{|c|c|c|c|c|}
\hline & $\begin{array}{l}\text { Healthy } \\
(n=12)\end{array}$ & $\begin{array}{l}\text { Convexity } \\
(n=20)\end{array}$ & $\begin{array}{c}\text { Concavity } \\
(n=14)\end{array}$ & $P$ \\
\hline Female, no. & 4 & 3 & 4 & NA \\
\hline Age, y & $77 \pm 5$ & $80 \pm 7$ & $79 \pm 8$ & .38 \\
\hline Weight, kg & $55 \pm 12$ & $48 \pm 10$ & $46 \pm 6$ & .058 \\
\hline Height, cm & $161 \pm 9$ & $158 \pm 7$ & $158 \pm 8$ & .63 \\
\hline BMI, $\mathrm{kg} / \mathrm{m}^{2}$ & $21 \pm 4$ & $19 \pm 4$ & $18 \pm 3$ & .12 \\
\hline $\mathrm{FEV}_{1}, \mathrm{~L}$ & $2.06 \pm 0.43$ & $1.06 \pm 0.49^{*}$ & $0.55 \pm 0.16^{* \dagger}$ & $<.001$ \\
\hline $\mathrm{FEV}_{1} \%$ predicted & $90.4 \pm 11.7$ & $48.2 \pm 18.9^{*}$ & $25.8 \pm 5.6 * \dagger$ & $<.001$ \\
\hline $\mathrm{FEV} / \mathrm{FVC}, \%$ & $76.1 \pm 5.2$ & $47.8 \pm 13.3^{*}$ & $39.1 \pm 14.1 *$ & $<.001$ \\
\hline FVC, L & $2.76 \pm 0.60$ & $2.07 \pm 0.73$ & $1.36 \pm 0.42 * \dagger$ & $<.001$ \\
\hline FVC $\%$ predicted & $95.3 \pm 11.7$ & $71.8 \pm 17.5^{*}$ & $49.8 \pm 15.8^{* \dagger}$ & $<.001$ \\
\hline $\mathrm{T}_{\mathrm{I}}, \mathrm{s}$ & $1.56 \pm 0.33$ & $1.26 \pm 0.49$ & $1.00 \pm 0.44^{*}$ & .01 \\
\hline $\mathrm{T}_{\mathrm{E}}, \mathrm{s}$ & $1.96 \pm 0.54$ & $2.03 \pm 1.04$ & $1.83 \pm 0.74$ & .80 \\
\hline $\mathrm{T}_{\text {tot }}, \mathrm{s}$ & $3.43 \pm 0.90$ & $3.31 \pm 1.37$ & $2.84 \pm 1.16$ & .40 \\
\hline $\mathrm{T}_{\mathrm{I}} / \mathrm{T}_{\text {tot }}$ & $0.45 \pm 0.03$ & $0.39 \pm 0.08$ & $0.35 \pm 0.03^{*}$ & .001 \\
\hline $\mathrm{V}_{\mathrm{T}}, \mathrm{L}$ & $0.58 \pm 0.19$ & $0.65 \pm 0.16$ & $0.52 \pm 0.18$ & .13 \\
\hline $\mathrm{V}_{\mathrm{T}} / \mathrm{T}_{\mathrm{I}}, \mathrm{L} / \mathrm{s}$ & $0.38 \pm 0.11$ & $0.56 \pm 0.20^{*}$ & $0.55 \pm 0.19$ & .01 \\
\hline $\mathrm{V}_{\mathrm{T}} / \mathrm{T}_{\mathrm{E}}, \mathrm{L} / \mathrm{s}$ & $0.31 \pm 0.11$ & $0.36 \pm 0.12$ & $0.30 \pm 0.09$ & .28 \\
\hline Rectangular area ratio & $0.664 \pm 0.069$ & $0.570 \pm 0.045^{*}$ & $0.456 \pm 0.08 * \dagger$ & $<.001$ \\
\hline $\begin{array}{l}\text { Values are mean } \pm \mathrm{SD} . \\
*=P=.01 \text { vs healthy } \\
\dagger=P=.01 \text { vs convexity } \\
\mathrm{NA}=\text { not applicable } \\
\mathrm{BMI}=\text { body mass index } \\
\mathrm{T}_{\mathrm{I}}=\text { inspiratory time } \\
\mathrm{T}_{\mathrm{E}}=\text { expiratory time } \\
\mathrm{T}_{\text {tot }}=\text { total breathing cycle time } \\
\mathrm{T}_{\mathrm{I}} / \mathrm{T}_{\text {tot }}=\text { duty cycle } \\
\mathrm{V}_{\mathrm{T}}=\text { tidal volume } \\
\mathrm{V}_{\mathrm{T}} / \mathrm{T}_{\mathrm{I}}=\text { mean inspiratory flow } \\
\mathrm{V}_{\mathrm{T}} / \mathrm{T}_{\mathrm{E}}=\text { mean expiratory flow }\end{array}$ & & & & \\
\hline
\end{tabular}

$30 \%$, GOLD stage 4, very severe air-flow obstruction) was also evaluated. The sensitivity, specificity, positive predictive value, negative predictive value, likelihood ratio of a positive test, likelihood ratio of a negative test, and diagnostic accuracy were $0.78,0.91,0.79,0.91,8.38,0.24$, and 0.87 , respectively. 
Table 3. Quality Indicators of the Indexes Used to Predict Air-Flow Obstruction

\begin{tabular}{|c|c|c|c|c|c|c|c|c|}
\hline & Cutoff & Sensitivity & Specificity & $\begin{array}{l}\text { Positive } \\
\text { Predictive } \\
\text { Value }\end{array}$ & $\begin{array}{l}\text { Negative } \\
\text { Predictive } \\
\text { Value }\end{array}$ & $\begin{array}{c}\text { Likelihood } \\
\text { Ratio of } \\
\text { Positive } \\
\text { Test }\end{array}$ & $\begin{array}{c}\text { Likelihood } \\
\text { Ratio of } \\
\text { Negative } \\
\text { Test }\end{array}$ & $\begin{array}{l}\text { Diagnostic } \\
\text { Accuracy }\end{array}$ \\
\hline $\mathrm{FEV}_{1} \%$ & 32.4 & 0.93 & 0.88 & 0.76 & 0.97 & 7.43 & 0.08 & 0.89 \\
\hline FVC\% & 60.8 & 0.79 & 0.88 & 0.73 & 0.90 & 6.29 & 0.24 & 0.85 \\
\hline $\mathrm{T}_{\mathrm{I}}$ & 1.06 & 0.79 & 0.75 & 0.58 & 0.89 & 3.14 & 0.29 & 0.76 \\
\hline $\mathrm{T}_{\mathrm{I}} / \mathrm{T}_{\text {tot }}$ & 0.39 & 0.86 & 0.78 & 0.63 & 0.93 & 3.92 & 0.18 & 0.80 \\
\hline FEV/FVC & 46.7 & 0.79 & 0.69 & 0.52 & 0.88 & 2.51 & 0.31 & 0.72 \\
\hline $\mathrm{V}_{\mathrm{T}} / \mathrm{T}_{\mathrm{I}}$ & 0.52 & 0.64 & 0.63 & 0.43 & 0.80 & 1.71 & 0.57 & 0.63 \\
\hline \multicolumn{9}{|c|}{$\begin{array}{l}\mathrm{T}_{\mathrm{I}}=\text { inspiratory time } \\
\mathrm{T}_{\text {tot }}=\text { total breathing cycle time } \\
\mathrm{V}_{\mathrm{T} / \mathrm{T}_{\mathrm{I}}=\text { mean inspiratory flow }}\end{array}$} \\
\hline
\end{tabular}

Table 4. Area Under the Receiver Operating Characteristic Curve

\begin{tabular}{lcc}
\hline \hline & AUC & $95 \% \mathrm{CI}$ \\
\hline $\mathrm{FEV}_{1} \%$ & 0.92 & $0.83-1.00$ \\
$\mathrm{FVC} \%$ & 0.89 & $0.80-0.99$ \\
$\mathrm{~T}_{\mathrm{I}} / \mathrm{T}_{\text {tot }}$ & 0.81 & $0.68-0.94$ \\
$\mathrm{FEV} / \mathrm{FVC}$ & 0.80 & $0.67-0.93$ \\
$\mathrm{~T}_{\mathrm{I}}$ & 0.77 & $0.61-0.93$ \\
$\mathrm{~V}_{\mathrm{T}} / \mathrm{T}_{\mathrm{I}}$ & 0.61 & $0.43-0.80$ \\
& & \\
\hline AUC $=$ area under curve & & \\
$\mathrm{T}_{\mathrm{I}}=$ inspiratory time & & \\
$\mathrm{T}_{\text {tot }}=$ total breathing cycle time & & \\
$\mathrm{V}_{\mathrm{T}} / \mathrm{T}_{\mathrm{I}}=$ mean inspiratory flow & & \\
\hline
\end{tabular}

\section{Discussion}

Our results show that the SEFV curve pattern changes in elderly COPD patients. In particular, concavity in the SEFV curve has been suggested as a useful index to predict very severe COPD in elderly patients. Several studies have shown SEFV curve characteristics in COPD patients ${ }^{4-10}$ from the study by Morris and Lane. ${ }^{3}$ They reported that the characteristic SEFV curve in COPD reached maximal expiratory flow early in the expiratory phase, and the time was correlated with the degree of air-flow obstruction and airway resistance. ${ }^{3}$ Moreover, the slope of the latter in the SEFV curve was correlated with air-flow obstruction and airway resistance. ${ }^{4}$ Baydur and MilicEmili9 ${ }^{9}$ studied visual assessment of the SEFV curve pattern in patients with obstructive and restrictive disorders, and reported a relationship between the SEFV curve pattern and expiratory flow limitation. Ma et $\mathrm{al}^{10}$ studied SEFV curve patterns during exercise and found that COPD patients had a trend to concavity, compared to normal subjects.

In the present study it was clear that the rectangular area ratio decreased more in the COPD subjects than in the normal subjects. Many COPD patients with more severe air-flow obstruction tend to show expiratory flow limitation, ${ }^{14}$ which causes dynamic hyperinflation, intrinsic PEEP, and dyspnea. ${ }^{15}$ Patients with concave SEFV curves tend to have expiratory flow limitation. ${ }^{9}$ Many of our COPD subjects had very severe air-flow obstruction (14 subjects with GOLD stage 4), and they had more concave SEFV curves. Moreover, our rectangular area ratio results show significant differences between the healthy subjects and the COPD subjects in the convexity group, probably due to expiratory flow limitation in subjects with moderate or severe COPD.

Baydur and Milic-Emili ${ }^{9}$ also reported that COPD patients with expiratory flow limitation often show SEFV curve convexity, so there must have been some expiratory flow limitation patients in the convexity group who tended to have decreased rectangular area ratio, more than patients without expiratory flow limitation. Indeed, expiratory flow in the convexity group tended to decrease linearly, despite the fact that many of the healthy subjects had a sinusoidal pattern (Fig. 3). However, we could not examine expiratory flow limitation, because of the problem with measuring sensitivity..$^{15}$ Expiratory flow limitation could have been examined by the method described by Hyatt, ${ }^{16}$ but it has a low accuracy to detect expiratory flow limitation. ${ }^{15}$

Our results show decreased $T_{I}$ and $T_{I} / T_{\text {tot }}$ and increased $\mathrm{V}_{\mathrm{T}} / \mathrm{T}_{\mathrm{I}}$ in the subjects who had concavity, compared with the healthy subjects. Morris et $\mathrm{al}^{3,4}$ found that flow deceleration immediately preceding inspiration affected the SEFV curve pattern. The premature start of inspiration also supports other studies ${ }^{17,18}$ that have found an increased time constant of the lung with increasing severity of obstruction. To increase ventilation in such COPD patients, expiration needs to be prolonged, since increased respiratory muscle activity is ineffective because of expiratory flow limitation. Shortening inspiration is one strategy for prolonging expiration and improving ventilation. ${ }^{17,18}$ Our subjects with concavity showed these results. 

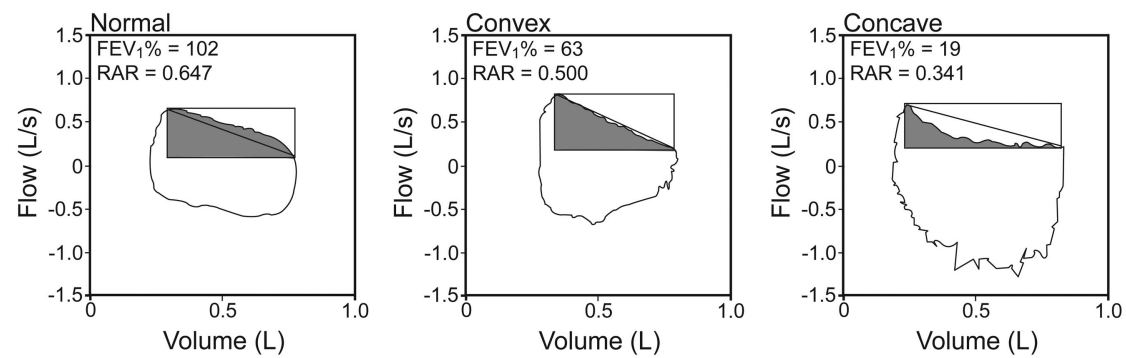

Fig. 3. Representative spontaneous flow-volume curves and rectangular area ratios (RARs).

$\mathrm{FEV}_{1} \%$ was the most powerful SEFV curve concavity predictor (area under the curve $0.92,95 \%$ CI $0.83-1.00$ ), and $\mathrm{FEV}_{1} \%$ had the highest sensitivity and specificity. The cutoff value was very low $\left(\mathrm{FEV}_{1} \% 32.4 \%\right)$, so $\mathrm{FEV}_{1} \%$ seems to be useful for detecting very severe air-flow obstruction. Moreover, an $\mathrm{FEV}_{1} \%$ cutoff value of $30 \%$ was also useful, with high sensitivity and specificity.

Morris et $\mathrm{al}^{3,4}$ and Colasanti et a $\mathrm{l}^{19}$ noted that the reason for SEFV curve concavity was dynamic airway compression or gas compression by high pleural pressure during expiration. These changes appear to affect the forced expiratory volume (FEV) curve pattern, but not the SEFV curve pattern in patients with moderate or severe COPD, but they affect the SEFV curve pattern (not only FEV) in patients with very severe COPD.

On the other hand, we found no significant relationship between age and SEFV curve pattern. This is important because the FEV curve pattern in elderly patients normally shows some signs of scalloping because of the loss of lung elasticity that occurs with aging. ${ }^{20}$ Since we did not include younger subjects, these effects could not be examined sufficiently, but the SEFV curve pattern did not appear to change with aging in our elderly COPD subjects.

The present study had certain limitations. First, the sample size was too small to fully examine the relevant factors responsible for SEFV curve pattern. Second, the subjects were not consecutive patients. Third, there was variation in the distribution of severity among the subjects. Finally, there were no subjects with mild airway obstruction (GOLD stage $1, \mathrm{FEV}_{1} \% \geq 80 \%$ ).

\section{Conclusions}

The SEFV curve pattern was concave in subjects with very severe airway obstruction. Therefore, elderly patients who cannot perform the FVC maneuver can be evaluated by assessment of the SEFV curve.

\section{REFERENCES}

1. ATS/ERS Task Force. General considerations for lung function testing. Eur Respir J 2005;26(1):153-161.

2. Dellaca RL, Duffy N, Pompilio PP, Aliverti A, Koulouris NG, Pedotti A, Calverley PM. Expiratory flow limitation detected by forced oscillation and negative expiratory pressure. Eur Respir J 2007;29(2):363-374.
3. Morris MJ, Lane DJ. Tidal expiratory flow patterns in airflow obstruction. Thorax 1981;36(2):135-142.

4. Morris MJ, Madgwick RG, Collyer I, Denby F, Lane DJ. Analysis of expiratory tidal flow patterns as a diagnostic tool in airflow obstruction. Eur Respir J 1998;12(5):1113-1117.

5. Williams EM, Madgwick RG, Morris MJ. Tidal expired airflow patterns in adults with airway obstruction. Eur Respir J 1998;12(5):1118-1123.

6. Morris MJ, Madgwick RG. Lane DJ. Analysis of tidal expiratory flow pattern in the assessment of histamine-induced bronchoconstriction. Thorax 1995;50(4):346-352.

7. Williams EM, Madgwick RG, Thomson AH, Morris MJ. Expiratory airflow patterns in children and adults with cystic fibrosis. Chest 2000;117(4):1078-1084.

8. Bake B, Houltz B, Sjölund P. High tidal end expiratory flow: an index of dynamic hyperinflation? Clin Physiol Funct Imaging 2007; 27(2):116-121.

9. Baydur A, Milic-Emili J. Expiratory flow limitation during spontaneous breathing: comparison of patients with restrictive and obstructive respiratory disorders. Chest 1997;112(4):1017-1023.

10. Ma S, Hecht A, Varga J, Rambod M, Morford S, Goto S, et al. Breathby-breath quantification of progressive airflow limitation during exercise in COPD: a new method. Respir Med 2010;104(3):389-396.

11. Johnson BD, Weisman IM, Zeballos RJ, Beck KC. Emerging concepts in the evaluation of ventilatory limitation during exercise: the exercise tidal flow-volume loop. Chest 1999;116(2):488-503.

12. Guenette JA, Chin RC, Cory JM, Webb KA, O'Donnell DE. Inspiratory capacity during exercise: measurement, analysis, and interpretation. Pulm Med 2013;2013:956081.

13. Hanamoto S, Ohsuji T, Tsuyuguchi I, Kawabata S, Kimura K. [Prediction formulas for pulmonary function tests expressed in linear and exponential form for healthy Japanese adults]. Nihon Kyobu Shikkan Gakkai Zasshi 1992;30(12):2051-2060. Article in Japanese.

14. Eltayara L, Becklake MR, Volta CA, Milic-Emili J. Relationship between chronic dyspnea and expiratory flow limitation in patients with chronic obstructive pulmonary disease. Am J Respir Crit Care Med 1996;153(3):1726-1734.

15. Calverley PM, Koulouris NG. Flow limitation and dynamic hyperinflation: key concepts in modern respiratory physiology. Eur Respir J 2005;25(1):186-199.

16. Hyatt RE. The interrelationship of pressure, flow and volume during various respiratory maneuvers in normal and emphysematous patients. Am Rev Respir Dis 1961;83:676-683.

17. Palecek F. Hyperinflation: control of functional residual lung capacity. Physiol Res 2001;50(3):221-230.

18. Gibson GJ. Pulmonary hyperinflation a clinical overview. Eur Respir J 1996;9(12):2640-2649.

19. Colasanti RL, Morris MJ, Madgwick RG, Sutton L, Williams EM. Analysis of tidal breathing profiles in cystic fibrosis and COPD. Chest 2004;125(3):901-908.

20. Janssens JP, Pache JC, Nicod LP. Physiological changes in respiratory function associated with ageing. Eur Respir J 1999;13(1):197-205. 